\title{
Poesías Americanas
}

\author{
DE NICARAGUA
}

LA TRAGEDIA DEL TORO'

Personajes

El Toro.-El Buey.-La Muchedumbre

Plaza de toros. Es la tarde. El sol brilla radiosamente en un cielo despejado. Alrededor del redondel hay un inmenso número de espectadores. En la arena, después de la muerte de varios bichos, la cuadrilla se prepara para retirarse triunfante. El primer espada, cerca de una huella sangrienta está gallardo y vestido de azul y oro, muleta y espada bajo el brazo. Los banderilleros visten de plata y ocre de Oriente. En las chaquetas de los picadores espejean las lentejuelas al resplandor de la tarde.

1 En Méndez Plancarte:

\section{GESTA DEL COSO}

Dramatis personae:

El toro, el buey, la muchedumbre.

América. Un coso. La tarde. El sol brilla radiosamente en un cielo despejado. En el anfiteatro hay un inmenso número de espectadores. En la arena, después de la muerte de varios toros, toda la cuadrilla se prepara para retirarse ttiunfante. El primer baluario, cerca de una huella sangrienta, está gallardo, vestido de azul y oro, muelta y espada bajo el brazo. Los banderilleros visten de amarillo y plata. En las chaquetas de los picadores espejean las lentejuelas al resplandor de la tarde. En el toril han quedado: un toro, hermoso y bravo, y un buey de servicio. Són de clarín. 
En el toril han quedado un toro hermoso y bravo, y el buey que sirve para sacar las reses de la plaza.

Son de clarín.

\section{La Muchedumbre}

¡Otro toro! Otro toro!

\section{EL BUEY}

\section{¿Has escuchado?}

Prepara empuje, cuernos y pellejo;

ha llegado tu turno, ira salvaje banderillas y picas que te acosan, aplausos al verdugo, al fin la muerte, ${ }^{2}$

y arriba, la impasible y solitaria contemplación del vasto firmamento. Yo, ridículo y ruin, soy el paciente esclavo. Soy el humillado eunuco, Mi testuz sabe resistir, y llevo sobre los pedregales la carreta, cuyas tuedas techinan y en cuya alta carga de pasto crujidor, a veces cantan versos los fuertes campesinos.

Mis ojos pensativos, al poeta dan sospechas de vidas misteriosas en que reina el enigma. Me complace meditar. Soy filósofo. Si sufro el golpe y la punzada, reflexiono que me concede Dios este derecho: espantarme las moscas con el rabo. Y sé que existe el matadero...

\section{EL TORO}

$$
\text { ¡Pampa! }
$$

¡Libertad! ¡Aire y sol! Yo era el robusto señor de la planicie, donde el aire mi bramido llevó cual son de un cuerno

\footnotetext{
2 En M. P. hay punto:
} 
que soplara un ${ }^{3}$ titán de anchos pulmones.

Con el pitón a flor de piel, yo erraba un tiempo en el gran mar de verdes hojas, cerca del cual corría el clato arroyo donde apagué la sed con belfo ardiente. Luego, fui bello rey de astas agudas; a $\mathrm{mi}$ voz respondían las montañas y mi estampa magnífica y soberbia hiciera arder de amor a Pasifae. Más de una vez el huracán indómito que hunde los puños desgarrando el roble, bajo el cálido cielo del estío sopló al paso su fuego en mis narices. Después fueron las luchas. Era el puma que me clavó sus garras en el flanco, y al que enterré los cuernos en el vientre. $Y$ tras el día caluroso, el suave aliento de la noche, el dulce sueño; sentir el alba, saludar la aurora que pone en $\mathrm{mi}$ testuz rosas y perlas; 5 ver la cuadriga de Tritón que avanza rasgando nubes con los cascos de oro, y alrededor de la carroza lírica, desaparecer las pálidas estrellas. Hoy aguardo martirio, escatnio y muerte.

\section{EL Buey}

¡Pobre declamador! Está a la entrada de la vida una esfinge sonriente. El azul es en veces negro. El astro se oculta, desaparece, muere. El hombre es aquí el poderoso traicionero.

Para él, temor. Yo he sido en mi llanura soberbio como tú. Sobre la grama bramé orgulloso y respiré soberbio.

\footnotetext{
3 M. P. suprime "un".

4 En M. P. hay coma.

5 En M. P. hay dos puntos.

6 En M. P. hay puntos suspensivos.
} 
Hoy vivo mutilado, como, engordo, la nuca inclino.

\section{EL Toro}

$Y$ bien: para ti el fresco pasto, tranquila vida, agua en el cubo, esperada vejez... A mí la roja capa del diestro, reto y burla, el ronco griterío, la arena donde clavo la pezuña, el torero que me engaña ágil y airoso y en mi carne entierra el arpón de la alegre banderilla, encarnizado tábano de hierro; la tempestad en mi pulmón de bruto; el resoplido que levanta el polvo; mi sed de muerte en desbordado instinto, mis músculos de bronce que la sangre hincha en hirviente plétora de vida; en mis ojos, ${ }^{7}$ dos llamas iracundas, la onda de rabia entre mi pecbo ${ }^{8}$ loca que echa su espuma a mi encendida fauce; el clarín del bizarro torilero que anima la apretada muchedumbre; el matador que enterrará hasta el pomo en mi carne la espada; la cuadriga de enguirnaldadas mulas que mi cuerpo arrastrará sangriento y palpitante; y el vitor y el aplauso a la estocada que en pleno corazón clava el acero. ¡Oh, nada más amargo! A mí los labios del arma fría que me da la muerte; tras el escarnio ${ }^{10}$ el crudo sacrificio, el horrible estertor de la agonía... en tanto que el azul ${ }^{11}$ sagrado, inmenso,

7 En M. P. se suprime la coma.

8 En M. P. se reemplaza con "por mis nervios".

9 En M. P.: "A mí,"

10 En M. P.: "tras el escarnio,"

y1 En M. P.: "en tanto que el azul, sagrado" [sin coma]. 
continúa sereno y en la altura ${ }^{12}$

el oro del gran sol rueda al poniente

en radiante apoteosis...

\section{La Muchedumbre}

¿Otro toro!

EL. BueY

¿Calla! ¡Muere! Es tu triunfo. ${ }^{13}$

\section{EL Toro}

Atroz sentencia!

¡Ayer el aire, el sol; hoy el verdugo!...

¿Qué peor que este martirio?...

\section{EL BUEY}

La impotencia.

EL TORO

¿Y qué más negro que la muerte. . ?

EL Buey

¡El yugo!

Madria.

RuBÉN DaRío

12 En M. P.: "continúa sereno, y en la altura," [entre comas].

13 En M. P.: se reemplaza con "tiempo". 
